\title{
OSOBINE LIČNOSTI KAO PREDIKTORI ŽELJENE ORGANIZACIJSKE KULTURE
}

\section{Dragana Radovanović', Predrag Okanović}

Odsek za psihologiju, Filozofski fakultet Novi Sad

Osnovni cilj ovog istraživanja je da se utvrdi da li osobine ličnosti mogu biti prediktori željene organizacijske kulture, i ukoliko jesu, koje su osobine povezane sa pojedinim faktorima organizacijske kulture. Istraživanje je sprovedeno na uzorku od 294 ispitanika (94 muškog i 200 ženskog pola). Uzorak čine studenti završnih godina $i$ apsolventi novosadskih fakulteta. U ovom istraživanju su korišćena dva instrumenta: Big Five Inventory i revidirani upitnik za procenu organizacijske kulture - Organizational Culture Profile. Ovaj upitnik čini sedam faktora organizacijske kulture: Kompetitivnost, Društvena odgovornost, Podrška (Timski rad), Inovativnost, Nagrađivanje, Orijentacija na učinak i Stabilnost. Sprovedena je dvosmerna multivarijantna analiza kovarijanse, gde su kao kontinuirani prediktori posmatrane dimenzije ličnosti merene BFI upitnikom, kao kategorijalni prediktori korišćeni pol i oblast obrazovanja, dok su kriterijumi sedam faktora organizacijske kulture, mereni OCP upitnikom. Testiranjem modela, kao značajni prediktori željene organizacijske kulture su se izdvojile dimenzije Prijatnost i Otvorenost, dok se od kategorijalnih prediktora nijedan nije pokazao kao značajan.

Ključne reči: Big Five Model, organizaciona kultura, Organizational Culture Profile upitnik

\footnotetext{
${ }^{1}$ Adresa autora: okanovici@neobee.net
} 


\section{Uvod}

Osobine ličnosti imaju veliku i značajnu ulogu u predviđanju i objašnjavanju organizacijskog ponašanja. Debata o tome šta je za predviđanje i objašnjavanje organizacijskog ponašanja važnije, dispozicije (ličnost) ili karakteristike neke situacije, je razrešena kroz interakcijski pristup, koji organizacijsko ponašanje definiše kao 'funkciju i dispozicija i situacija' (Johns \& Saks, 2008, str. 42). Drugim rečima, da bismo razumeli i predvideli neko organizacijsko ponašanje moramo da znamo nešto i o ličnosti pojedinca, kao i o okruženju u kojem taj pojedinac radi. Jedna od najvažnijih implikacija interakcionističkog pristupa je da su neke osobine ličnosti poželjne (čak i ključne) u nekim organizacijskim kontekstima. Ključni koncept je 'fit' (podudaranje) između osobe i organizacije u najširem smislu.

Razvoj Big Five modela je takođe doprineo ispitivanju i povezivanju osobina ličnosti sa varijablama organizacijskog ponašanja. Big Five model (Norman, 1967, prema John \& Srivastava, 1999; Goldberg, 1993, prema Smederevac i Mitrović, 2006) je nastao u okviru leksičke paradigme. Osnovna vrlina ovog modela je snažna empirijska utemeljenost i konceptualna obuhvatnost. Autori kao što su Sosir i Goldberg (Saucer \& Goldberg, 1996, prema Knežević, Džamonja i Đurić-Jočić, 2004) naglašavaju da leksička hipoteza obezbeđuje osnovu za deskriptivni, ali ne i kauzalni model ličnosti, jer se jezik u najvećoj meri odnosi na opisne, a ne uzročne karakteristike ličnosti. Big Five model podrazumeva postojanje pet osnovnih dimenzija ličnosti: ekstraverzija, neuroticizam, prijatnost, savesnost i otvorenost (John \& Srivastava, 1999).

Istraživanja u okviru organizacijske psihologije su povezivala dimenzije Big Five modela sa varijablama kao što su uspešnost, motivacija, zadovoljstvo poslom, profesionalne preferencije i druge (Judge, Klinger, Simon \& Wen Fen Yang, 2008).

Organizacijska kultura se definiše preko 'vrednosti i verovanja koje dele zaposleni u nekoj organizaciji i koja je u osnovi identiteta organizacije' (Kreitner, Kinicki \& Buelens, 1999, str. 54). Pod vrednostima u okviru ovog konteksta možemo podrazumevati poznatu Olportovu formulaciju da su to verovanja u skladu sa kojima čovek deluje, preferirajući određene postupke u odnosu na neke druge njima suprotne (Majstorović, 1995). Organizacijska kultura predstavlja važan konstrukt u organizacijskoj psihologiji, kao i u samoj praksi jer omogućava zaposlenima da se identifikuju sa organizacijom, utiče na predanost i omogućava lakše oblikovanje ponašanja zaposlenih unutar 
neke organizacije. O'Rajli (O'Reilly et al., 1991, prema Judge \& Cable, 1997) je u svom istraživanju identifikovao 8 faktora koji odgovaraju najčešćim dimenzijama koje su se navodile u literaturi, a koje su u vezi sa proučavanjem organizacijske kulture. Ti faktori su: Inovativnost, Orijentisanost na detalje, Orijentacija na učinak, Agresivnost, Podrška (Kooperativnost), Nagrađivanje (Pravednost), Timska orijentacija i Odlučnost.

Interakcionistički pristup $\mathrm{u}$ proučavanju organizacijskog ponašanja daje osnove za pretpostavku da je odabir određenog tipa organizacijske kulture uslovljen osobinama ličnosti. 'Individue tragaju za situacijama koje su kongruentne sa njihovom ličnošću' (Judge \& Cable, 1997, str. 364), što ukazuje na to da će i kandidati za posao 'tražiti' organizacije, odnosno birati onu organizacijsku kulturu koja odgovara njihovim osobinama ličnosti. Istraživanja O'Rajlija i saradnika su potvrdila ove pretpostavke (O'Reilly et al., 1991, prema Judge \& Cable, 1997). Dalje u svojim istraživanjima, Džadž i Kejbl (Judge \& Cable, 1997) su se bavili ispitivanjima osobina ličnosti petofaktorskog modela kao prediktora osam faktora organizacijske kulture dobijenim u okviru istraživanja O'Rajlija i saradnika. Nalazi njihovog istraživanja ukazuju na sledeće relacije: Emocionalna stabilnost se pokazala kao negativni prediktor za faktore Inovativnost i Odlučnost; Ekstraverzija se pokazala kao pozitivni preditor za faktore Agresivnost, Orijentisanost na učinak i Timska orijentacija, dok se pokazala kao negativni prediktor za faktor Kooperativnost; Otvorenost se pokazala kao pozitivan prediktor za faktor Inovativnost i Orijentisanost na detalje, dok je negativan prediktor za faktor Agresivnost; Prijatnost je u pozitivnoj relaciji sa faktorima Kooperativnost i Timska orijentacija, dok je negativan prediktor za faktore: Agresivnost, Orijentisanost na učinak, Odlučnost i Pravednost; i na kraju, dimenzija Savesnost se pokazala kao značajan prediktor za faktore Orijentisanost na detalje i na učinak, dok je u negativnoj relaciji sa faktorima Inovativnost i Timska orijentacija.

U ovom istraživanju je prvi put upotrebljen revidirani Upitnik za procenu organizacijske kulture OCP (Organisational Culture Profile; Saross, Gray, Densten \& Cooper, 2005) u kome su ajtemi za procenu faktora organizacijske kulture Likertovog tipa i koji je nastojao da prevaziđe ograničenja Q-sort metoda koji je korišćen u istraživanju O'Rajlija i saradnika, kao i istraživanju Džadža i Kejbla. Originalni upitnik O'Rajlija i saradnika se sastojao od 54 ajtema koji su obuhvatali osam faktora organizacijske kulture: Inovativnost, Orijentacija ka detaljima, Orijentacija na učinak, Agresivnost, Podrška, Nagrađivanje, Timska orijentacija i Odlučnost. Kao glavni nedostatak ovog upitnika Saroš i saradnici navode individualno zadavanje i korišćenje Q-sort 
metodologije. Q-sort metodologija podrazumeva da ispitanici rangiraju ajteme u unapred određen broj kategorija, što otežava primenu ovog upitnika na velikim uzorcima. Revidirani upitnik sa ajtemima Likertovog tipa, autori su primenili na populaciju australijskih menadžera i dobili su sedam faktora organizacijske kulture: Orijentacija na učinak, Društvena odgovornost, Podrška, Nagrađivanje (pravednost), Stabilnost, Kompetitivnost i Inovativnost.

Osnovni cilj ovog istraživanja je ispitivanje osobina ličnosti, pola i oblasti obrazovanja kao prediktora željene organizacijske kulture. Budući da se koristi upitnik koji ima drugačiju faktorsku strukturu od onog koji su koristili autori Džadž i Kejbl, u ovom istraživanju nisu pretpostavljene relacije između osobina ličnosti i faktora željene organizacijske kulture.

\section{Metod}

\section{Uzorak}

Istraživanje je sprovedeno na ukupnom uzorku od 294 ispitanika oba pola. Prosečna starost ispitanika je 24,4 godine, a raspon godina se kreće od 18 do 30 godina. Uzorak čine studenti završnih godina i apsolventi novosadskih fakulteta, s obzirom da oni predstavljaju buduće kandidate za posao. Istraživanje je sprovedeno u periodu novembar-decembar 2008. godine.

Tabela 1. Uzorak ispitanika

\begin{tabular}{ccccccc}
\hline & prosek & \multicolumn{2}{c}{ pol } & \multicolumn{3}{c}{ oblast obrazovanja } \\
$\mathrm{N}$ & godina & $\mathrm{m}$ & ž & humanistička & tehnička & ostalo \\
\hline 294 & 24.4 & $32 \%$ & $68 . \%$ & $54.1 \%$ & $29.3 \%$ & $16.6 \%$ \\
\hline
\end{tabular}

Instrumenti

Organizational Culture Profile (OCP, Saross et al., 2005) sadrži 28 ajtema Likertovog tipa i obuhvata 7 faktora organizacione kulture: Kompetitivnost (orijentacija na postignuće, akcenat na kvalitet, različitost od drugih), Društvena odgovornost (uviđavnost prema društvenoj sredini, dobra reputacija, jasna filozofija poslovanja), Podrška (timska orijentacija, briga o zaposlenima, negovanje saradnje među zaposlenima), Inovativnost (otvorenost za inovacije, spremnost za preuzimanje rizika, individualna odgovornost), Nagrađivanje 
(pravedan odnos prema zaposlenima, omogućavanje visoke zarade za dobar učinak, pružanje pohvale za dobar učinak), Orijentacija na učinak (postavljanje visokih očekivanja od zaposlenih, vrednovanje najboljih rezultata, visok radni entuzijazam) i Stabilnost (stabilno poslovanje, sigurnost zaposlenja, smireni odnosi među zaposlenima). Pouzdanost ovog upitnika je $\alpha=, 75$ (Saross et al., 2005). Ovaj upitnik je dobijen modifikacijom skraćene verzije originalnog OCP upitnika Džadža i Kejbla (Judge \& Cable, 1997). Upitnik je sadržao 40 ajtema i koristio Q-sort metodologiju, koja nije pogodna za administriranje u praksi. U okviru ovog istraživanja revidiranim upitnikom je procenjivana željena, a ne realna organizacijska kultura. Ispitanici su dobili instrukciju da procenjuju karakteristike organizacije u odnosu na njihovu idealnu organizaciju. Skor na sedam faktora organizacijske kulture dobijen je sabiranjem vrednosti ajtema koji čine određeni faktor po ključu. Upitnik je primenjen uz dozvolu autora Džejmsa Saroša dobijenu 08.12.2008. godine.

The Big Five Inventory (BFI; John, Donahue \& Kentle, 1991, prema John \& Srivastava, 1999) se sastoji od 44 tvrdnje koje se odnose na mišljenja, osećanja i ponašanja. Ispitanici preko petostepene Likertove skale izražavaju stepen saglasnosti sa svakom tvrdnjom. Upitnik se sastoji od pet subskala: Otvore-nost (intelekt, dovitljivost, sklonost ka razmišljanju), Savesnost (ispunjavanje obaveza, organizovanost, urednost, pažljivost), Ekstraverzija (društvenost, prijateljstvo, pričljivost, socijabilnost), Neuroticizam (anksioznost, napetost, sklonost ka doživljavanju negativnih emocija) i Prijatnost (saosećajnost, ljubaznost, odanost). Pouzdanost ovog upitnika je $\alpha=, 82$ (John \& Srivastava, 1999).

Ovim testovima je priključen i set demografskih varijabli kao što su pol i oblast obrazovanja. Oblast obrazovanja je operacionalizovana kao varijabla kategorijalnog tipa i ima tri vrednosti: humanistička, tehnička i ostalo, u odnosu na to koji fakultet pohađaju ispitanici: filozofski, tehnički ili neki drugi. Oblast obrazovanja su ispitanici samostalno navodili, i nakon kategorisanja odgovora dobijene su dve kategorije: humanistička $(\mathrm{N}=159)$ i tehnička $(\mathrm{N}=86)$. S obzirom da su preostale kategorije oblasti obrazovanja bile vrlo male, 49 ispitanika je isključeno iz analiza u kojima je korišćena ova varijabla.

\section{Rezultati}

Sprovedena je dvosmerna multivarijatna analiza kovarijanse, gde su kao kontinuirani prediktori posmatrane dimenzije ličnosti merene BFI upitnikom, 
a kao kategorijalni prediktori su korišćeni pol i oblast obrazovanja. Kriterijske varijable su sedam faktora OCP upitnika. Ova analiza sprovedena je na uzorku od 242 ispitanika. Iz uzorka su izostavljeni oni ispitanici koji se u odnosu na varijablu oblast obrazovanja nisu mogli svrstati u kategoriju humanistička (filozofski fakultet) ili tehnička orijentacija.

Tabela 5. Multivarijatni efekti prediktora

\begin{tabular}{lccc}
\hline & Wilks' Lambda & $\mathrm{F}$ & $\mathrm{p}$ \\
\hline Ekstraverzija & 0.958 & 1.391 & 0.210 \\
Prijatnost & 0.903 & 3.400 & $\mathbf{0 . 0 0 2}$ \\
Savesnost & 0.963 & 1.205 & 0.301 \\
Neuroticizam & 0.976 & 0.779 & 0.605 \\
Otvorenost & 0.913 & 3.028 & $\mathbf{0 . 0 0 5}$ \\
Pol & 0.974 & 0.838 & 0.557 \\
Oblast obrazovanja & 0.992 & 0.271 & 0.965 \\
Pol*Oblast obrazovanja & 0.986 & 0.461 & 0.862 \\
\hline
\end{tabular}

Sprovedena analiza ukazuje na to da su se kao značajni prediktori izdvojile dimenzije ličnosti Prijatnost i Otvorenost, dok se od kategorijalnih prediktora nijedna varijabla nije izdvojila kao značajna. Da bi se jasnije video odnos ovih varijabli, kao i to za koje faktore organizacijske kulture su one značajne, sprovedene su univarijatne analize varijanse za svaki faktor organizacijske kulture.

Tabela 6. Efekti prediktora za faktor Kompetitivnost

\begin{tabular}{|c|c|c|c|c|c|c|}
\hline \multicolumn{7}{|c|}{ KOMPETITIVNOST } \\
\hline \multicolumn{7}{|c|}{$R=.199 R^{2}=.0039 F(228)=1.1628 p=.322$} \\
\hline & $\mathrm{df}$ & SS & MS & $\mathrm{F}$ & $\mathrm{p}$ & Beta \\
\hline Ekstraverzija & 1 & .692 & .692 & .151 & .698 & .029 \\
\hline Prijatnost & 1 & .090 & .090 & .020 & .889 & -.010 \\
\hline Savesnost & 1 & .073 & .073 & .016 & .900 & -.009 \\
\hline Neuroticizam & 1 & 1.052 & 1.052 & .229 & .632 & -.037 \\
\hline Otvorenost & 1 & 20.042 & 20.042 & 4.371 & .038 & .145 \\
\hline Pol & 1 & 1.958 & 1.958 & .427 & .514 & -.049 \\
\hline Oblast obrazovanja & 1 & .606 & .606 & .132 & .717 & .028 \\
\hline Pol $\times$ Oblast obrazovanja & 1 & 8.977 & 8.977 & 1.958 & .163 & .101 \\
\hline
\end{tabular}


Tabela 7. Efekti prediktora za faktor Inovativnost

\begin{tabular}{|c|c|c|c|c|c|c|}
\hline \multicolumn{7}{|c|}{$\begin{array}{c}\text { INOVATIVNOST } \\
R=.227 R^{2}=.051 \quad F(228)=1.543 p=.143\end{array}$} \\
\hline & $\mathrm{df}$ & SS & MS & $\mathrm{F}$ & $\mathrm{p}$ & Beta \\
\hline Ekstraverzija & 1 & .065 & .065 & .015 & .901 & .009 \\
\hline Prijatnost & 1 & .872 & .872 & .207 & .649 & .033 \\
\hline Savesnost & 1 & .606 & .606 & .144 & .704 & .028 \\
\hline Neuroticizam & 1 & .109 & .109 & .026 & .872 & -.012 \\
\hline Otvorenost & 1 & 31.008 & 31.008 & 7.379 & .007 & .187 \\
\hline Pol & 1 & 1.355 & 1.355 & .323 & .571 & -.042 \\
\hline Oblast obrazovanja & 1 & .005 & .005 & .001 & .973 & .003 \\
\hline $\begin{array}{l}\text { Pol } \times \text { Oblast } \\
\text { obrazovanja }\end{array}$ & 1 & 1.168 & 1.168 & .278 & .598 & .038 \\
\hline
\end{tabular}

Tabela 8. Efekti prediktora za faktor Orijentacija na učinak

\begin{tabular}{|c|c|c|c|c|c|c|}
\hline \multicolumn{7}{|c|}{ 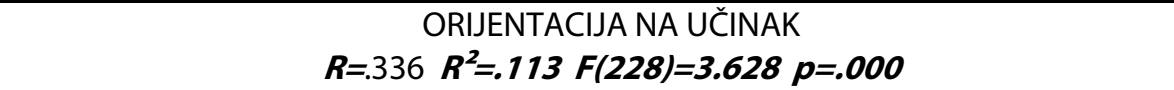 } \\
\hline & df & SS & MS & $\mathrm{F}$ & $\mathrm{p}$ & Beta \\
\hline Ekstraverzija & 1 & 2.059 & 2.059 & .671 & .413 & .060 \\
\hline Prijatnost & 1 & .293 & .293 & .095 & .758 & .021 \\
\hline Savesnost & 1 & 3.409 & 3.409 & 1.111 & .293 & .076 \\
\hline Neuroticizam & 1 & 2.969 & 2.969 & .968 & .326 & .073 \\
\hline Otvorenost & 1 & 57.388 & 57.388 & 18.704 & .000 & .287 \\
\hline Pol & 1 & .085 & .085 & .028 & .868 & -.012 \\
\hline Oblast obrazovanja & 1 & .045 & .045 & .015 & .904 & .009 \\
\hline $\begin{array}{l}\text { Pol } \times \text { Oblast } \\
\text { obrazovanja }\end{array}$ & 1 & .531 & .531 & .173 & .678 & .029 \\
\hline
\end{tabular}

Prve tri univarijatne analize pokazuju da se dimenzija Otvorenost pokazala kao značajan prediktor za faktore Kompetitivnost, Inovativnost i Orijentacija na učinak. Potrebno je napomenuti da multiple korelacije za Kompetitivnost i Inovativnost nisu statistički značajne, ali smatramo da ta činjenica ne ugrožava značajnost nalaza o vezi između Otvorenosti i navedenih faktora.

Podatak da Otvorenost predstavlja značajan prediktor pomenuta tri faktora jeste u skladu sa određenjem kako same dimenzije, tako i faktora koje ona predviđa. Da bi potencijalni kandidati za posao vrednovali kompanije koje su inovativne, kompetitivne i orijentisane na učinak, potrebno je da i sami budu otvoreni za promene i nova iskustva. 
Tabela 9. Efekti prediktora za faktor Društvena odgovornost

\begin{tabular}{lcrrrrr}
\hline \multicolumn{7}{c}{ DRUŠTVENA ODGOVORNOST } \\
& $\mathrm{R}=.271 \mathrm{R}^{2}=.073 \mathrm{~F}(228)=2.256$ & $\mathrm{p}=.024$ & & \\
& $\mathrm{df}$ & \multicolumn{1}{c}{$\mathrm{SS}$} & \multicolumn{1}{c}{$\mathrm{MS}$} & \multicolumn{1}{c}{$\mathrm{F}$} & $\mathrm{p}$ & Beta \\
\hline Ekstraverzija & 1 & 2.970 & 2.970 & .694 & .406 & .062 \\
Prijatnost & 1 & 17.894 & 17.894 & 4.181 & .042 & .145 \\
Savesnost & 1 & 1.028 & 1.028 & .240 & .625 & -.036 \\
Neuroticizam & 1 & 0.300 & 0.300 & .070 & .791 & .020 \\
Otvorenost & 1 & 14.407 & 14.407 & 3.367 & .068 & .125 \\
Pol & 1 & 4.231 & 4.231 & .989 & .321 & -.073 \\
Oblast obrazovanja & 1 & 2.139 & 2.139 & .500 & .480 & .054 \\
Pol $\times$ Oblast & 1 & 7.304 & 7.304 & 1.707 & .193 & .092 \\
obrazovanja & & & & & &
\end{tabular}

Tabela 10. Efekti prediktora za faktor Stabilnost

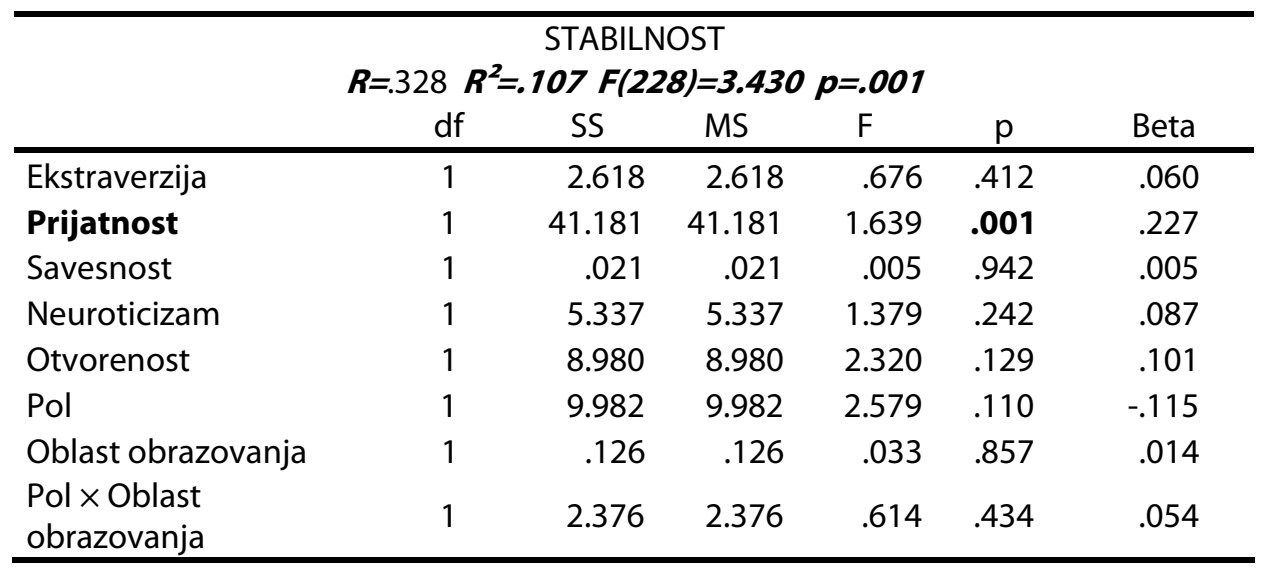

Dimenzija Prijatnost se pokazala kao značajan prediktor za faktore Društvena odgovornost i Stabilnost. Kao i kod prethodnih analiza i ovde su dobijeni nalazi u skladu sa teorijskim određenjima i prediktora i kriterijuma. 
Tabela 11. Efekti prediktora za faktor Podrška

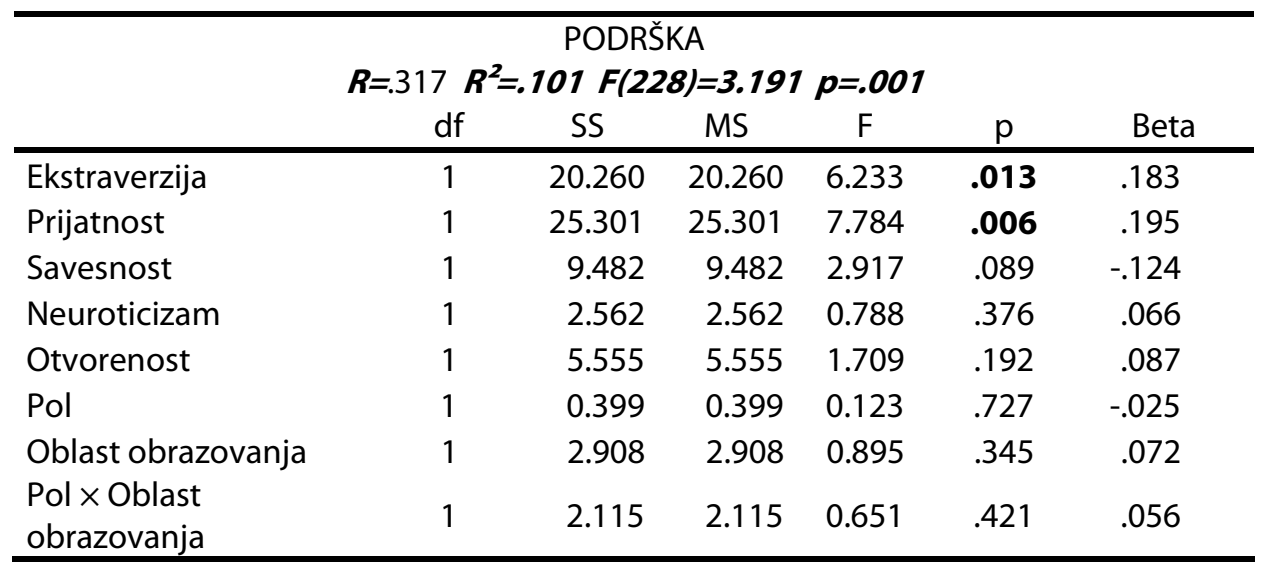

Faktor Podrška koji se odnosi na saradnju, timski rad i slobodnu razmenu informacija značajne prediktore ima u dimenzijama Ekstraverzija i Prijatnost. Ekstraverzija kao dimenzija se nije pokazala kao značajna na testiranju modela, ali je značajan prediktor za ovaj faktor. Kandidati koji su društveniji i u komunikaciji otvoreniji, i koji pored toga teže dobrim odnosima i odsustvu konflikata, će više birati organizacije koje kao dominantnu karakteristiku imaju podršku, odnosno gde se neguje timski rad.

Tabela 12. Efekti prediktora za faktor Nagradivanje

\begin{tabular}{|c|c|c|c|c|c|c|}
\hline \multicolumn{7}{|c|}{ NAGRAĐIVANJE } \\
\hline & $\mathrm{df}$ & SS & MS & $\mathrm{F}$ & $p$ & Beta \\
\hline Ekstraverzija & 1 & .135 & .135 & .055 & .815 & .017 \\
\hline Prijatnost & 1 & 15.601 & 15.601 & 6.325 & .013 & .173 \\
\hline Savesnost & 1 & .096 & .096 & .039 & .843 & .014 \\
\hline Neuroticizam & 1 & .422 & .422 & .171 & .679 & .030 \\
\hline Otvorenost & 1 & 28.752 & 28.752 & 11.657 & .001 & .224 \\
\hline Pol & 1 & 6.515 & 6.515 & 2.641 & .105 & -.115 \\
\hline Oblast obrazovanja & 1 & .906 & .906 & .367 & .545 & .045 \\
\hline $\begin{array}{l}\text { Pol } \times \text { Oblast } \\
\text { obrazovanja }\end{array}$ & 1 & .011 & .011 & .004 & .947 & .005 \\
\hline
\end{tabular}

Za faktor Nagrađivanje su se kao značajni prediktori pokazali Prijat-nost $i$ Otvorenost. Faktor nagrađivanje se odnosi na pravedno nagrađivanje zaposlenih za njihov učinak, te će osobe koje teže ka dobrim i harmoničnim 
odnosima, kao i promenama, novim iskustvima više preferirati ovakve organizacije.

\section{Diskusija}

Ispitivanjem osobina ličnosti kao prediktora željene organizacijske kulture utvrđeno je da su se dimenzije Prijatnost i Otvorenost pokazale kao značajne prilikom testiranja celokupnog modela. Kategorijalni prediktori se nisu pokazali kao značajni.

Otvorenost se pokazala kao značajan prediktor za tri faktora organizacijske kulture: Kompetitivnost, Inovativnost i Orijentacija na učinak. Dobijeni nalaz ukazuje da se preko skora na toj dimenziji može doneti pretpostavka o željenoj organizacijskoj kulturi. Kandidati za posao koji su otvoreni ka novim iskustvima, promenama, skloni imaginaciji i razvijenog intelekta će preferirati organizacije u okviru kojih će moći da izražavaju ove osobine, a to su upravo organizacije koje odlikuju kompetitivnost, inovativnost i orijentacija na učinak. Rezultat koji se odnosi na povezivanje Otvorenosti i Inovativnosti je u skladu sa rezultatom Džadža i Kejbla (Judge \& Cable, 1997). U svom istraživanju autori su takođe potvrdili povezanost ove dimenzije i Inovativnosti. Iako nije u direktnoj vezi sa ovim nalazima, značajno je napomenuti i nalaz meta analize koju je sproveo Bel, s obzirom da se odnosi na dimenziju Otvorenosti (Bell, 2007, prema Judge et al., 2008). Naime, povezujući Otvorenost i efektivnost timova, utvrdio je da je za efektivne timove važno da budu homogeni po stepenu izraženosti ove dimenzije (bilo da je ona niska ili visoka). Za praktičare ovaj nalaz može da bude od koristi prilikom formiranja timova u okviru određene organizacijske kulture.

Za faktore Društvena odgovornost i Stabilnost se kao statistički značajan prediktor izdvojila dimenzija Prijatnost. Dakle, može se pretpostaviti da će kandidati za posao koji teže skladnim odnosima sa drugim ljudima preferirati kompanije koje se odnose odgovorno prema svojim zaposlenima, ali i prema društvu.

Prijatnost i Ekstraverzija predviđaju Podršku kao faktor organizacijske kulture. Faktor podrške označava saradnju, timski rad i orijentaciju na ljude, te je kombinacija skorova na ove dve dimenzije kao prediktora ovog faktora prilično jasna i logična. Dodatno, potvrdu za ovaj nalaz nalazimo i u meta analizi Barika, 
Maunta i Džadža (Barrick, Mount \& Judge, 2001, prema Judge et al., 2008) koja ističe da Prijatnost i Ekstraverzija predviđaju timski uspeh u nekoj organizaciji

Na kraju, faktor Nagrađivanje prediktore ima u dimenzijama Prijatnost i Otvorenost. Nagrađivanje stimuliše razvoj novih ideja i pristupa što može objasniti vezu sa Otvorenošću, dok pravedno nagrađivanje podstiče bolje i harmoničnije odnose među zaposlenima.

Dobijeni nalazi ukazuju na to da se osobine ličnosti mogu smatrati prediktorima željene organizacijske kulture, prvenstveno Otvorenost i Prijatnost. Za praktičare ovaj nalaz može da bude od koristi prilikom procesa selekcije, kada na osnovu ovih dimenzija mogu da pretpostave da li će se kandidat za posao uklopiti u organizacijsku kulturu koja je karakteristična za tu organizaciju. Dodatno, ovi nalazi mogu da budu od koristi u procesima planiranja i razvoja karijere zaposlenih. Imajući na umu ove nalaze može se olakšati proces donošenja odluka prilikom formiranja timova ili pokretanja novih projekata. U brzom poslovnom okruženju gde je idealni 'fit' između zaposlenih i organizacija jedan od imperativa poslovanja, od izuzetnog značaja za praksu je poznavanje i upotreba različitih instrumenata, kao i nalaza istraživanja iz ove oblasti.

Ograničenja ovog istraživanja se prvenstveno odnose na uzorak, koji je u ovom istraživanju prigodan i formiraju ga studenti. Buduća istraživanja bi svakako trebalo sprovesti na većem i više ujednačenom uzorku. Dodatno, značajno bi bilo sprovesti faktorizaciju i proveru metrijskih karakteristika upitnika OCP na uzorku zaposlenih, jer bi se na taj način utvrdili faktori realne organizacijske kulture na domaćoj populaciji. Tada bi se ovaj upitnik mogao primenjivati i u praksi, kako u procesima selekcije, tako i u procesima planiranja karijere i razvoja zaposlenih. Dodatno, ovakav instrument, koji je lak za administriranje i ne zahteva puno vremena za popunjavanje, može biti koristan dijagnostički instrument $\mathrm{u}$ organizacijskom kontekstu. Za buduća istraživanja koja bi se bavila relacijama osobina ličnosti i organizacijske kulture bi bilo interesantno posmatrati ove relacije u odnosu na demografske varijable kao što su dužina radnog staža, hijerarhijski nivo pozicije, delatnost kompanije i druge.

\section{Zaključak}

Osnovni zaključci ovog istraživanja ukazuju na opravdanost daljih istraživanja koja bi se bavila ispitivanjem relacija između osobina ličnosti i organizacijske kulture. U ovom istraživanju je utvrđeno da su se osobine Prijatnost i 
Otvorenost pokazale kao značajni prediktori željene organizacijske kulture. Dobijene relacije između osobina ličnosti i faktora organizacijske kulture jesu u skladu sa teorijskim određenjima dimenzija, ali i nalazima prethodnih istraživanja (Judge \& Cable, 1997; Barrick, Mount \& Judge, 2001, prema Judge et al., 2008). Bilo bi značajno da se ove relacije ispitaju i na uzorku zaposlenih osoba. Uzorak zaposlenih osoba bi omogućio ispitivanje faktora realne organizacijske kulture, kao i proveru metrijskih karakteristika OCP upitnika. U pogledu ispitivanih relacija bilo bi značajno videti koje osobine ličnosti najviše predviđaju realnu organizacijsku kulturu i koliko se ti nalazi razlikuju od nalaza dobijenih ovim istraživanjem.

\section{Reference}

John, O.P. \& Srivastava, S. (1999). The Big Five Trait Taxonomy: History, Measurement, \& Theoretical Perspectives. In: Lawrence A. Pervin \& Oliver P. John (Eds.). Handbook of Personality: Theory \& Research. New York: The Guilford Press, $102-138$.

Johns, G. \& Saks, A. (2008). Organizational behaviour: understanding and managing life at work. Toronto: Pearson Pretince Hall

Judge, T.A. \& Cable, D.M. (1997). Applicant personality, organizational culture \& organizational attraction, Personnel Psychology, 50(2), 359-94.

Judge, T.A., Klinger, R., Simon, S.L. \& Wen Fen Yang, I. (2008). 'The contribution of personality to organizational behaviour \& psychology: findings, criticism \& future research directions', Social \& Personality Psychology Compass, 2(5), 1982-2000.

Knežević, G., Džamonja, T. i Đurić-Jočić, D. (2004). Petofaktorski model ličnosti. Beograd: Centar za primenjenu psihologiju.

Kreitner, R., Kinicki, A. \& Buelens, M. (1999). Organizational Behavior. London: McGraw-Hill

Majstorović, N. (1995): „Vrednosti - pregled pristupa, definicija i naših istrašivanja", u: Đurić, Đ. (ur.): Ličnost u višekulturnom društvu, Vol.2, Odsek za psihologiju, Filozofski fakultet, Novi Sad, 194-209. 
Saross, J., Gray, J., Densten, I. \& Cooper, B. (2005). The Organizational culture profile revisited \& revised: an Australian perspective, Australian Journal of Management, 30(1), 160-182.

Smederevac, S. i Mitrović, D. (2006). Ličnost - metodi i modeli. Beograd: Centar za primenjenu psihologiju 


\title{
PERSONALITY TRAITS AS PREDICTORS OF DESIRABLE ORGANIZATIONAL CULTURE
}

\author{
Dragana Radovanović and Predrag Okanović
}

The main aim of this research is to establish whether personality traits can be predictors of desirable organizational culture, and, if so, which traits are related to particular factors of organizational culture. The research was conducted on a sample of 294 participants ( 94 males and 200 females). The sample comprised the senior students and graduates of the University of Novi Sad. Two instruments were employed : the Big Five Inventory (BFI) and a revised questionnaire for organizational culture assessment - Organizational Culture Profile. The latter measures seven factors: Competitiveness, Social Responsibility, Supportiveness, Innovation, Stability, Emphasis on Rewards and Performance Orientation. A two - way multivariate analysis of covariance was performed. Gender and the field of study were categorical predictors, the continuous predictors were the BFI scores, and the criteria were the scores on the seven organizational culture factors. The significant predictors of the desirable organizational culture were Agreeableness and Openness, while none of the categorical predictors was significant.

Key words: The Big Five Model, organizational culture, the OCP questionnaire 